\title{
Influence of Structure and Physical-Mechanical Characteristics of Threads on the Strength of Binding the Books
}

\author{
Svitlana HAVENKO*,***, Edmundas KIBIRKŠTIS**, Laura GEGECKIENE***, Svitlana \\ KHADZHYNOVA*, Myroslava KADYLIAK*** \\ *Technical University of Lodz, Skorupki 10/12, r. 105, 90-924 Lodz, Poland, E-mail: svitlana.havenko@p.lodz.pl; \\ E-mail: svitlana.khadzhynowa@p.lodz.pl \\ **Kaunas University of Technology, Department of Manufacturing Engineering, Studentu 56-316, LT-51424, Kaunas, \\ Lithuania; E-mail: edmundas.kibirkstis@ktu.lt \\ **Kaunas University of Technology, Department of Manufacturing Engineering, Studentu 56-317, LT-51424, Kaunas, \\ Lithuania; E-mail: laura.gegeckiene@ktu.lt \\ ***Ukrainian Academy of Printing, Pid Holoskom 19, 79020,Lviv, Ukraine; E-mail: havenko@point.lviv.ua; \\ E-mail: kadelak@ukr.net
}

cross $^{\text {ref }}$ http://dx.doi.org/10.5755/j01.mech.25.4.22774

\section{Introduction}

The technology of book blocks fastening involves the use of diverse modern equipment, where various methods of book sections or book blocks fastening are made with cotton, polyamide or viscose threads with the formation of different types of stitches, depending on the thickness of the block, the type of paper, edition design, etc. [1-3].

However, well-known today technology of sewing book blocks with threads and equipment have a number of unresolved problems related to the problem of increasing the tribological properties of threads, by which book sections and book blocks are being sewn in the machines of the skid type, and related to the establishment of close connections between the working bodies of the machine, in order to optimize sewing process [4-7].

The purpose of the work was to study the influence of the structure of cotton and polyamide threads with applied antifriction coatings, on their technological and operational characteristics for improving of the technological process of sewing and increase of the strength of book blocks sections binding.

As the object of the research were chosen cotton and polyamide threads that fastened book backs of book blocks made of offset paper Mega matt and chalk paper PROXIMA on a thread-automatic machine.

For sewing of book blocks, matte threads of the number 30 with the thickness $0.3 \mathrm{~mm}$ in 3 folding and with tear strength up to $16 \mathrm{~N}$ (GOST 6309-93), and polyamide threads of the brand $50 \mathrm{~K}$ in two folding with the thickness of $0.20-0.22 \mathrm{~mm}$ with a tear strength of $27 \mathrm{~N}$ (TU-6-1300206256-53-93) were used.

To reduce the friction coefficient and breakage of the threads, antifriction coatings were used to control the thickness of the film according to the developed method.

\section{Experimental details}

\subsection{Problem formulation}

An important step in calculating the strength of threads for book sections and book blocks sewing is the choice of the strength criterion. The long-term strength of the threads with arbitrary external influences we consider based on the durability of materials, namely, the correlation between the time of destruction and the corresponding load unchanged in time.

Let's introduce the damage function $f(t)$, which is equal to zero in the initial state and one unit at the moment of breaking of the thread: $u_{(0)}=0 ; U\left(t_{1}\right)=1$, where $t_{1}$ is the time before the breaking of the thread with the arbitrary law of the change in the stresses in time. We assume that the rate of accumulation of damage depends on $u(t)$ and on some function $\Psi(t)$

Function $\Psi(t)$ is determined by the arbitrary functions $F$ and $\varphi_{1}$ :

$$
\psi(t)=\int_{0}^{t} F(t-\tau) \phi(\sigma) d \tau .
$$

$u_{(0)}=0$.

Let's integrate (1) taking into consideration

$$
\int_{0}^{u} \frac{d u}{f(u)}=\int_{0}^{t} \psi(\xi) d \xi .
$$

Remembering, that $u\left(t_{1}\right)=1$, we get:

$$
1=\int_{0}^{t_{1}} d \xi \int_{0}^{\xi} F(\xi-\tau) \phi(\sigma) d \tau .
$$

Choosing the function of influence in the form of:

$$
F(\xi-\tau)=F_{0}(\xi-\tau)^{m} \quad(m=n)
$$

And transforming the double integral (3) we write this equation as:

$$
1=\int_{0}^{t_{1}}\left(t_{1}-\tau\right) \phi(\sigma) d \tau .
$$

For determination of the given function we shall take the result of the studies on the durability of cotton and polyamide threads, which will enable us to find: 


$$
t_{0}=t_{0}\left(\sigma_{0}\right)
$$

where: $t_{0}$ - time before the destruction; $\sigma_{0}=$ const - does not depend on the time of tension (load).

At $\sigma_{0}=$ const from the formula (5) we get:

$$
\phi\left(\sigma_{0}\right)=\frac{1+n}{t_{0}^{1+n}\left(\sigma_{0}\right)},
$$

and

$$
\frac{1}{1+n}=\int_{0}^{t_{1}}\left(t_{1}-\tau\right) n \frac{d \tau}{t_{0}^{1+n}(\sigma)}
$$

The ratio (7) will be a condition of long-term durability and determines the time $\mathrm{t} 1$ before the destruction of the given load law $\sigma(t)$ and the experimentally determined longevity function $t_{0}=t_{0}\left(\sigma_{0}\right)$.

For $n=0$, from the condition (5) follows the wellknown criterion of long-term Bailey strength:

$$
1=\int_{0}^{t_{1}} \frac{d \tau}{t_{0}(\sigma)} .
$$

Taking into consideration the law of durability:

$$
t_{0}=B \sigma_{0}^{b}
$$

We shall write equation 5 in the form of:

$$
\frac{B^{1+n}}{1+n}=\int_{0}^{t_{1}}\left(t_{1}-\tau\right) \sigma^{n} \sigma^{b(1+n)}(\tau) d \tau,
$$

assuming that, $(1+n)=1$, we have:

$$
B^{\frac{1}{b}}=\int_{0}^{t_{1}}\left(t_{1}-\tau\right)^{\frac{1}{b}} d \sigma(\tau) .
$$

According to the criterion of O.A. Ilyushin (1) for an un-axial stressed condition:

$$
1=\int_{0}^{t_{1}} \frac{d \sigma_{11}(\tau)}{\sigma_{0}\left(t_{1}-\tau\right)} .
$$

As it can be seen, with the certain meaning: $n=$ $=-1+1 / b$ criteria of long-term durability of V. Moskitin and O. Ilyushin coincide. Consequently, no matter which criteria of strength to take, to predict the strength of the process of sewing (formed stitches) in the basis of their longevity is the material (cotton, polyamide), which is determined experimentally.

B. Komman developed the theory of fibres and threads destruction, known as "kinetics of the break". In the classical theory it is assumed that the border of the fibres (threads) strength corresponds to their weakest cross-section. The theory of "kinetics of the break" suggests that the thread, being under the load $t$, is being de- stroyed in the cross section, which has at the least time for sewing. Based on this theory, we determine the probability $\Phi_{l}\left(t_{l}\right)$ that a thread with the length 1 and with this load character will break in the interval $0<t<t_{1}$. The type of function $\Phi_{l}\left(t_{l}\right)$ depends on the load and nature of the thread.

$$
P_{l}\left(t_{1}\right)=1-\exp \left\{-l\left[\int_{0}^{t_{1}} t[\sigma(t)] d t\right]^{k}\right\},
$$

where: $k$ - positive component.

Taking into consideration that $\sigma(t)=\sigma_{0}=$ const :

$$
P_{l}\left(t_{0}\right)=1-\exp \left\{-l\left[t\left(\sigma_{0}\right)\right]^{k} t_{0}^{k}\right\}
$$

For the average time of sewing (durability) we have:

$$
E\left\{t_{0}\right\}=l^{-\frac{1}{k}} G\left(1+\frac{1}{k}\right)\left[t\left(\sigma_{0}\right)\right]^{-1} .
$$

According to the (10) the middle time of thread life for the constant law of durability will be:

$$
E\left\{t_{0}\right\}=l^{-\frac{1}{k}} G\left(1+\frac{1}{k}\right) B \sigma_{0}^{-b} .
$$

And for the exponential:

$$
E\left\{t_{0}\right\}=l^{-\frac{1}{k}} G\left(1+\frac{1}{k}\right) B \exp \left(-2 \sigma_{0}\right),
$$

$$
\frac{\left[G\left(1+\frac{1}{k}\right) B\right]^{(1+n) t_{1}}}{\frac{1+n}{l^{k(1+n)}}}=\int_{0}^{1}\left(t_{1}-\tau\right)^{n \sigma^{b(1+n)}}(\tau) d \tau .
$$

\section{Results}

3.1. Physical-mechanical and operational properties of threads

The experimental actual linear density of the polyamide thread is 56.4 tex, and of the cotton thread is 66.32 tex.

The results of tests of physical and mechanical properties of polyamide and cotton threads for sewing of book blocks are shown in diagrams (Figs. 1-4).

The relative breaking load of the untreated cotton thread is $25.16 \mathrm{cN} /$ tex, and of the polyamide $-44.27 \mathrm{cN} / \mathrm{tex}$, and of the cotton thread, processed with antifriction solution $-26.75 \mathrm{cN} /$ tex, polyamide thread $-44.23 \mathrm{cN} /$ tex. Oiled threads are easily unwound from coils of sewing machines, but they do not provide a significant increase in sewing strength. As the studies show, the relative elongation of the oiled polyamide filament increases by 2 percent. Extruding the threads for 24 hours in distilled water increases the 
relative elongation of the oiled thread by 2 percent. The percentage moisture content on the oiled thread does not affect.

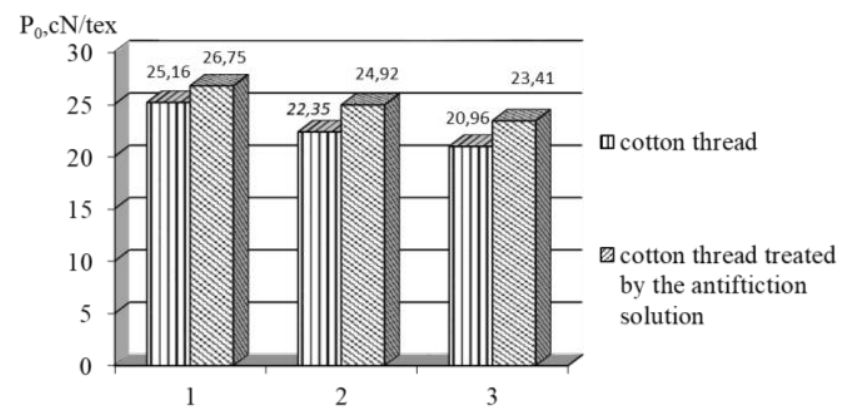

Fig. 1 Diagram of relative breaking load: 1 under normal conditions $\left(20^{\circ} \mathrm{C}, 65 \%\right), 2$ in wet condition $\left(20^{\circ} \mathrm{C}\right.$, $100 \%), 3$ in a digester $\left(20^{\circ} \mathrm{C}, 35 \%\right)$

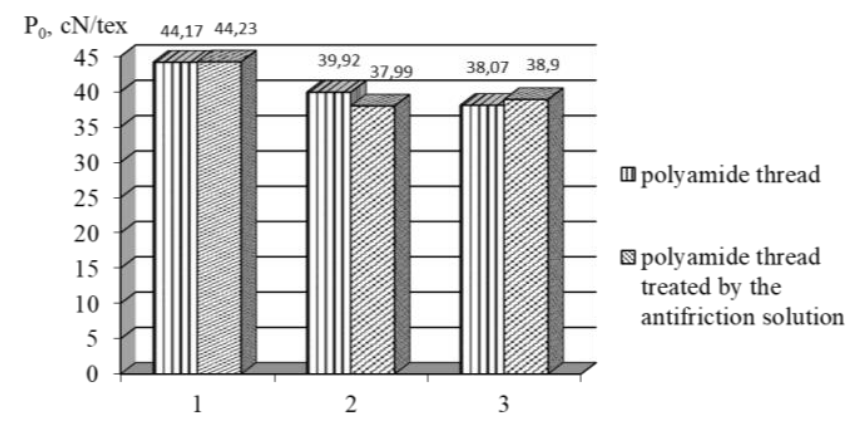

Fig. 2 Diagram of relative breaking load: 1 under normal conditions $\left(20^{\circ} \mathrm{C}, 65 \%\right), 2$ in wet condition $\left(20^{\circ} \mathrm{C}\right.$, $100 \%), 3$ in a digester $\left(20^{\circ} \mathrm{C}, 35 \%\right)$

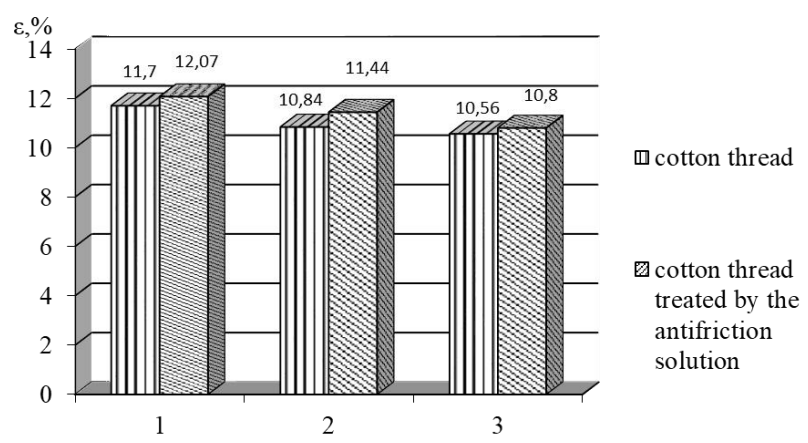

Fig. 3 Diagram of relative elongation: 1 under normal conditions $\left(20^{\circ} \mathrm{C}, 65 \%\right), 2$ in the wet condition $\left(20^{\circ} \mathrm{C}, 100 \%\right), 3$ - an extractor $\left(20^{\circ} \mathrm{C}, 35 \%\right)$

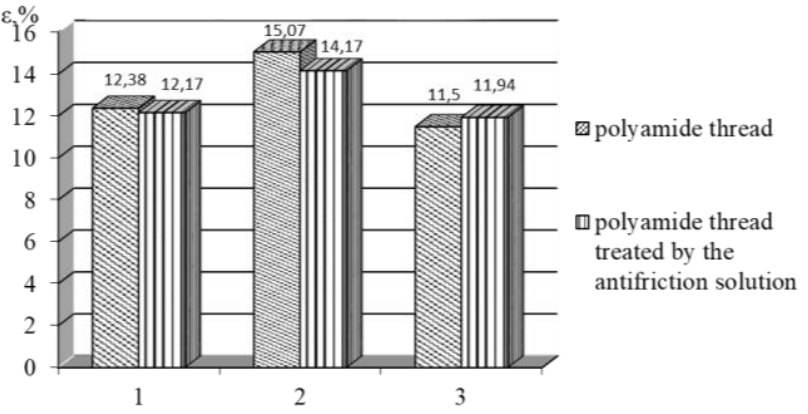

Fig. 4 Diagram of relative elongation: 1 - 1 under normal conditions $\left(20^{\circ} \mathrm{C}, 65 \%\right), 2$ - in a wet condition $\left(20^{\circ} \mathrm{C}, 100 \%\right), 3$ - an extractor $\left(20^{\circ} \mathrm{C}, 35 \%\right)$

Studies show that the greater the strength of the fibers, the greater the strength of the threads will be, their discontinuity and elongation. By the curve "elongation loading" for polyamide or cotton threads, the change in their absolute and relative elongation can be described. In particular, according to the angle of inclination of the curve we can determine the module of the first kind, which characterizes the resistance of the material to elongation. Studies show that the lightweight spinning fibre has a low modulus. Curves "deformation - stress" for the investigated threads at different humidity are different. Thus, with increasing of humidity in the polyamide and cotton fibres, the module of the first kind (in polyamide from 0.80 to 0.03 , and in cotton from 1.00 to 0.33 ) decreases, and the breaking elongation increases (in polyamide from 0.80 to 1.58 , and in cotton from 1.00 to 1.11 )

Our antifriction solution for the treatment of cotton and polyamide threads increases the breaking strength, elongation, and also reduces the coefficient of friction on the steel. In connection with the above listed indicators, the number of breaks per $1 \mathrm{~kg}$ of threads decreases.

The results are shown in Table. 1

The force of threads friction during the process of their stretching through the thread-wound machine system when sewing book blocks is essential for the quality of their fastening. Experiments have confirmed that oiling of cotton fibres significantly reduces the coefficient of friction. So, the non-oiled cotton thread has a coefficient of friction when passing through the steel needle holders $\mu=0.25$, and oiled -0.14 .

Indicators of physical and mechanical properties of cotton and polyamide threads

\begin{tabular}{|c|c|c|c|c|c|}
\hline $\begin{array}{c}\text { Types of } \\
\text { threads }\end{array}$ & Antifriction coating weight, \% & $\begin{array}{c}\text { Relative breaking } \\
\text { force, gs/tex }\end{array}$ & $\begin{array}{c}\text { Relative breaking } \\
\text { elongation, \% }\end{array}$ & $\begin{array}{c}\text { Coefficient of threads } \\
\text { friction on metal }\end{array}$ & $\begin{array}{c}\text { Break off threads } \\
\text { for 1 kg, per unit. }\end{array}$ \\
\hline Cotton & $\begin{array}{c}\text { Mineral oil of T type (vaseline) 55\% } \\
\text { Sulfobutyl oleate 15\% } \\
\text { Stearin 30\% }\end{array}$ & 33.5 & 12.3 & 0.160 & 0.28 \\
\hline Polyamide & $\begin{array}{c}10 \% \text { sulphonated castor oil 61\% } \\
5 \% \text { oleic acid 7\% } \\
\text { Triethanolamine 32\% }\end{array}$ & 44.5 & 12.4 & 0.125 & 0.017 \\
\hline
\end{tabular}

\subsection{Electron microscopic research of threads}

It is the matter of common knowledge that form of the cross-section of the chemical fiber, which serves as the basis for the thread, depends on the features of its macrostructure and affects their physical and mechanical properties, namely sorption, thermal, resistance to abra- sion, gloss, etc. Microstructure of fibers is characterized by the shape of their cross-section, the presence of radial heterogeneity, micro and macroporosity. Empty fibers have greater strength, greater degree of molecular orientation, less elongation at break than fibers of the cylindrical form. Polyamide threads have a porosity of about a micron size. 
Fig. 5 shows the outer structure of polyamide (a) and cotton (b) threads.

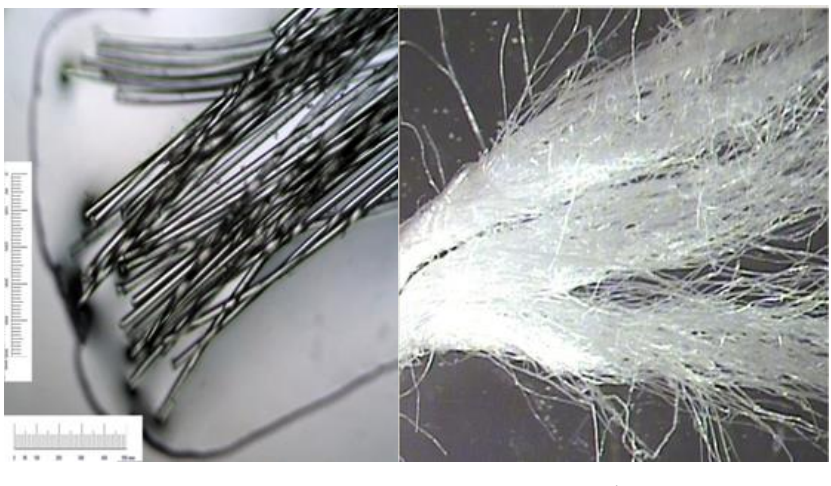

a

$\mathrm{b}$

Fig. 5 The outer structure of threads x3000: a-polyamide, b-cotton

Microscopic investigations made possible to reveal the presence of non-uniformity and unevenness of fiber threads, the appearance of which may be caused by the heterogeneity of the polymer melt, by the change in technological processes, the heterogeneity of the sizes of the filer during the formation of threads, and the hydrodynamic instability of their formation. Microscopic studies of thickening on fibers of threads explain their nature. Fig. 6 shows variants of thickening in threads.

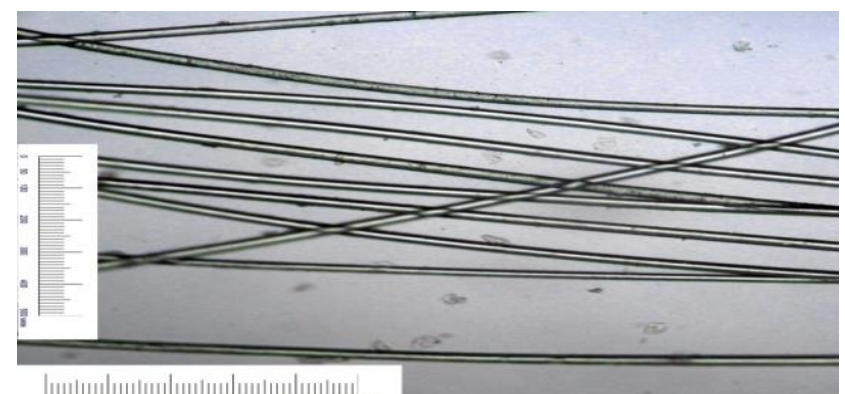

a

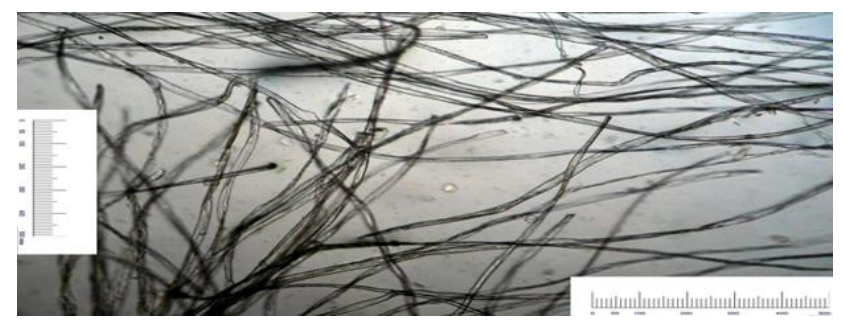

b

Fig. 6 Thickening of threads x3000: a-polyamide, b-cotton

Obviously, the reasons may be: 1) thickening without heterogeneous inclusions (which may be due to the uneven viscosity of the polyamide melt in the formation of polyamide fiber); 2) thickening due to the presence of a unit of pigment particles; 3) thickening with gas inclusions.

These defects affect the shape of the cross-section of threads. One of the reasons for their appearance may be the process of fibers hardening (this is especially true for polyamide threads). The difference between the ability to deform a thin surface layer and the inner core leads to more or less developed non-circular cross-sectional shapes (true for cotton threads) (Fig. 7 a).

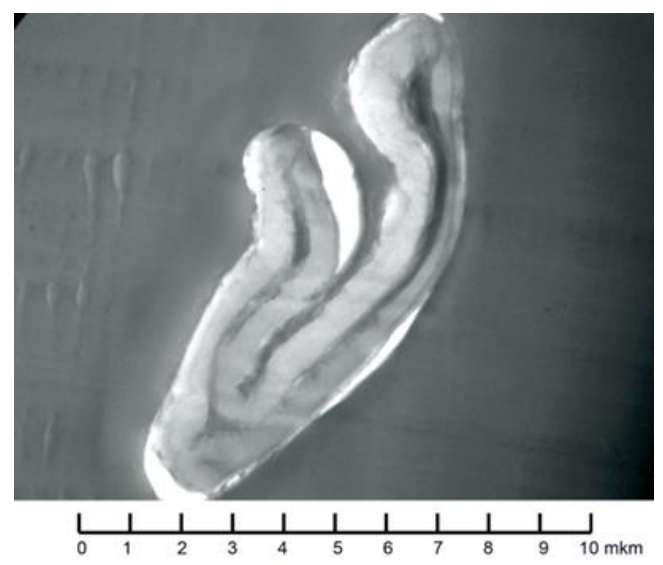

a

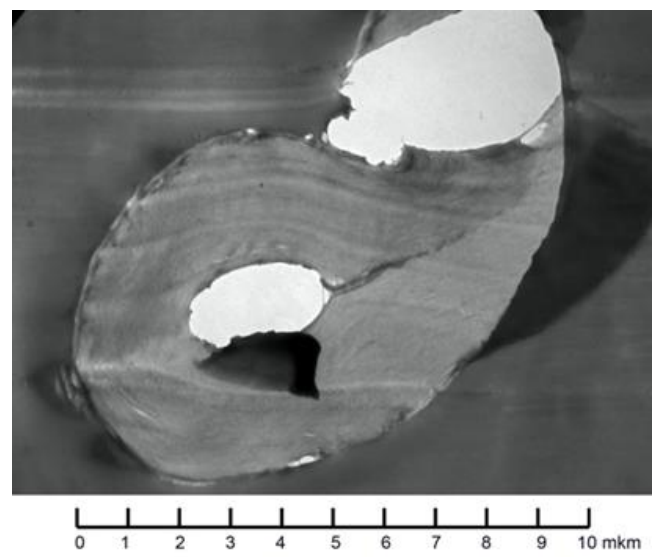

b

Fig. 7 Cross-section of cotton thread x2200: a-polyamide, b-cotton

The gradient of the rigidity of the surface layer and, accordingly, the deviation of the cross-sectional shape from the circular will be the greater, as the greater the solvent removal rate and the smaller the diffusion coefficient within the fiber strands will be. It means that the process of the threads drying while their manufacture influences the shape of the cross-section. In some pores and capillaries with the size of several tens of micrometers are present in the structure, and in some they are absent. The mechanism of formation of large pores and long capillaries, which are radically placed along the cross-section of the fiber, is not known completely. Some authors associate this effect with volume change and cracking of the hardened polymer layer. The others argue that because of the certain defective spots, or "holes", on the surface of the fibers of threads the interpenetration of the non-solvent takes place. The mass transfer between the pores goes faster than the diffusion through the hardened layer, hence the rapid growth of the capillaries in the direction of gradients concentration occurs. For cotton fibers (threads) radial heterogeneity of the structure is very common. Fibers are surrounded by an impenetrable and non-dyed thin layer, followed by a shell and core (Fig. 7, b).

The dense homogeneous shell of the cross-section affects the mechanical and sorption properties of the threads. As the magnitude of the shell increases, the water absorption of the threads increases too. It is probable that the formation of small, about of one micrometer is the result of phase distribution processes, accompanied by a 
change in volume. It has been experimentally proved that the best mechanical properties have threads in fibers of which there are fewer pores and voids and there are smaller but developed fibrils.

There are two types of processes that occur in fibers when exposed to water (aqueous solutions) or atmospheric moisture. The first group causes a quick change in the size and density. The existing connection between the kinetics of sorption and the kinetics of relaxation processes confirms the fact that the latter proceed immediately after the action of moisture. The second group of processes involves a change in mechanical properties (Fig. 8).

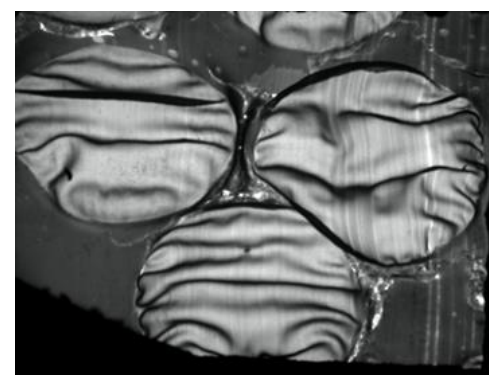

a

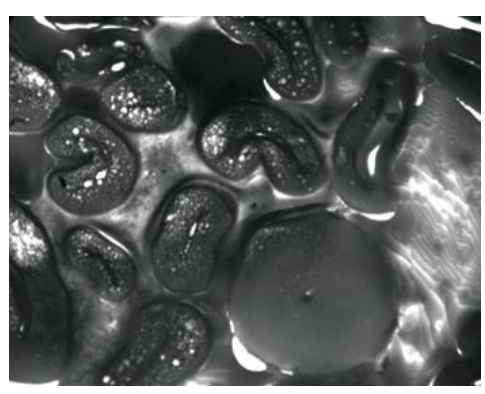

$\mathrm{b}$

Fig. 8 Section of fibers which have been treated in antifriction solutions x1500: a-polyamide, b-cotton

Polyamide fiber (thread) under the influence of moisture increases its length by 2-20 percent. According to the classical theory of anisotropy of swelling, there is such an effect - an increase in the transverse dimensions of the oriented fibers should be greater than the change in longitudinal dimensions and it depends on the orientation factor. However, experimental studies show that polyamide fibers (threads) under the influence of water increase their length by 6.9 percent, and their diameter changes only on 1.9 percent. This is due to the fact that under the influence of water on the fiber irreversible structural changes take place in it. Researches of the microscopic structure of polyamide threads $(0.2-0.22 \mathrm{~mm}$ in thickness) and cotton threads (0.30 $\mathrm{mm}$ in thickness) confirmed that threads tendency to twisting and to the formation of knots which cause breaks while sewing of book sections or book blocks on the NBM takes place because of an uneven thickness and heterogeneous structure of the fibers from which they are formed.

Thus, the results of electron microscopic studies of threads showed that additional treating of threads in glutinous and antifriction solutions leads to a smoothing of the fibers structure, what greatly improves the sewing process of the blocks itself on modern high-speed book binding machines, and increases the quality of book binding.

An analysis of the microfilaments studies of cotton threads showed that the molecules in their fibers are oriented not along the length, but are placed along the spiral, making the angle of the fibers close to 30 degrees. It is probable that the elongation of such threads can occur due to the stretching of the spiral (similar to the spring), what explains the low modulus of the cotton fiber.

Electron microscopic studies of the threads surface after passing through a thread-wiring system, steel needles and hooks in a thread-sewing machine, show the presence of grooves in which the fiber is slightly stiffled, and with a higher sewing speed, that is, large loads, there is a noticeable deformation that causes the destruction of the surface in the center of the grooves. The concave form of the groove is probably due to a stronger elasticity in the center where the greatest deformation takes place.

Thus, in the course of research, the nature of the damage to the thread surface during the book blocks sewing and influence of its deformation properties on the strength of the publications fastening were revealed.

The optimization of the process of creating stitches during sewing of book sections was carried out (Fig.9).

The graphs (Fig. 9 - Fig. 11) and equations of the regression lines of the first and second order shown on the graphs allow us to come to the following conclusions:

- on average, when the load is increased by $1000 \mathrm{~g}$, the thread extends: for a brochure stitch on $2.0 \mathrm{~mm}$, for a staggered stitch on $1.7 \mathrm{~mm}$, and for a binding stitch on $2.4 \mathrm{~mm}$;

- compliance (load sensitivity) of the stitch is a variable load value $x$ :

for a brochure stitch $d y / d x=3.2-0.8 \times x(\mathrm{~mm} / \mathrm{kg})$;

for a staggered stitch $d y / d x=2.8-0.8 \times x(\mathrm{~mm} / \mathrm{kg})$;

for a binder stitch $d y / d x=3.52-0.8 \times x(\mathrm{~mm} / \mathrm{kg})$.

That is, with increasing of the load from $0.1 \mathrm{~kg}$ to $3 \mathrm{~kg}$, the compliance decreases:

brochure stitch from 3.12 to $0.8(\mathrm{~mm} / \mathrm{kg})$; compliance range $R=3.12-0,8=2.32(\mathrm{~mm} / \mathrm{kg})$; staggered stitch from 2.72 to $0.4(\mathrm{~mm} / \mathrm{kg})$; compliance range $R=2.72-0.4=2.32(\mathrm{~mm} / \mathrm{kg})$; binder stitch from 3.42 to $1.1(\mathrm{~mm} / \mathrm{kg})$; compliance range $R=3.42-1.1=2.32(\mathrm{~mm} / \mathrm{kg})$.

On Fig. 12 the dependencies of the elongation of the polyamide thread $(\mathrm{mm})$ depending on the load on the brochure (a), staggered (b) and binding (c) stitches made by it are being given.

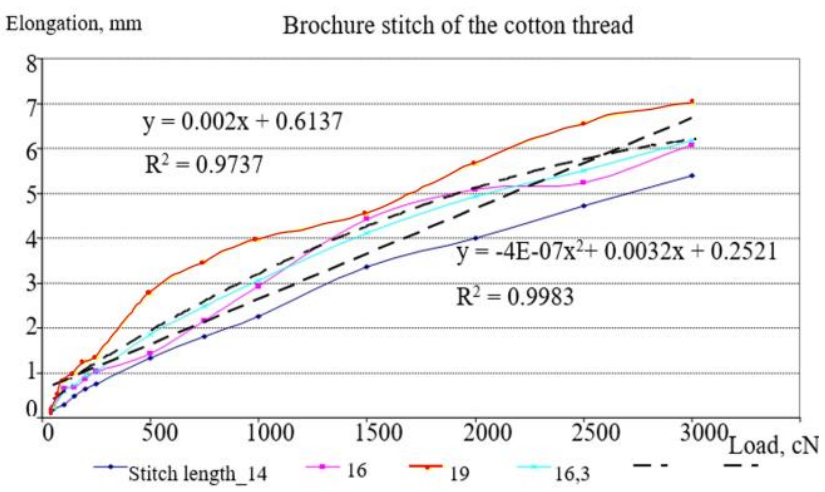

Fig. 9 Extension of the cotton thread $(\mathrm{mm})$ depending on the load for the brochure stitch $(14 \mathrm{~mm}, 16 \mathrm{~mm}$, $19 \mathrm{~mm})$

The graphic dependencies (Fig. 12) and equations of the regression lines of the first and second order shown in the graphs make it possible to come to the following conclusions: 
- on average, with an increase in load per $1000 \mathrm{~g}$, the polyamide thread extends: for a brochure stitch on $2.6 \mathrm{~mm}$, a staggered stitch on $2.1 \mathrm{~mm}$, and a binding stitch on $3.0 \mathrm{~mm}$.

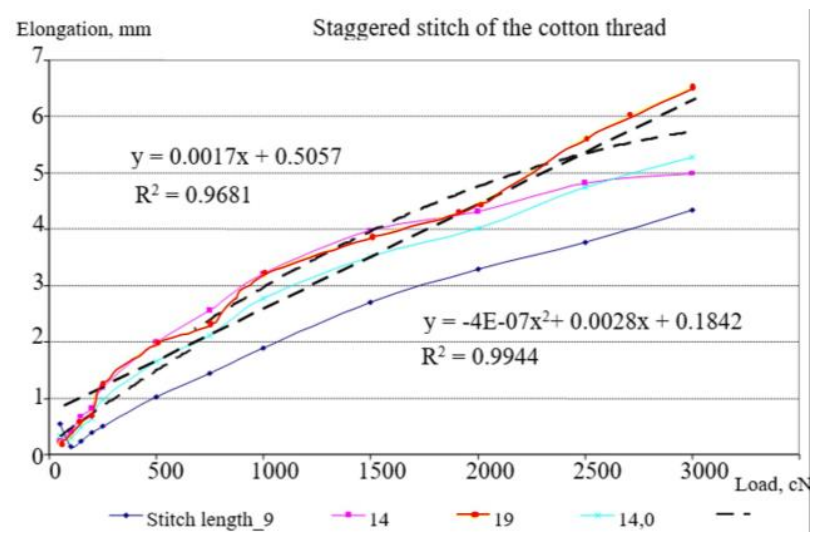

Fig. 10 Extension of cotton thread (mm) depending on the load on the formed by it staggered stitch, length (9 mm, $14 \mathrm{~mm}, 19 \mathrm{~mm}$ )

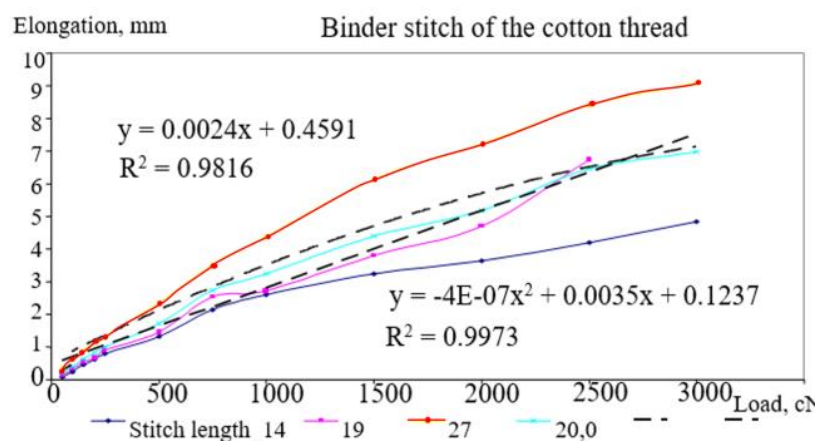

Fig. 11 Extension of cotton thread (mm) depending on the load on the formed by it binder stitch, length $9 \mathrm{~mm}, 14 \mathrm{~mm}, 19 \mathrm{~mm}$

Analysis of the study of the strength of the book blocks sewing section by section showed that the average value of the force of pulling out the section from the block is from 125.8 to $420.6 \mathrm{~N}$ for a resilient binding stitch with the length of 14 to $27 \mathrm{~mm}$ (with the use of a polyamide thread) and from 96.4 to $206.3 \mathrm{~N}$ With the use of cotton thread.). The average value of the force of pulling a section from the block when sewn with a binder stitch of the same length from the polyamide thread is from 153.5 to $345.9 \mathrm{~N}$, and from 125.8 to $327.8 \mathrm{~N}$ when the cotton thread is used.

Compliance (load sensitivity) of the stitch is a variable load value, that is, when the load is increased from $0.1 \mathrm{~kg}$ to $3 \mathrm{~kg}$, the compliance decreases: for the brochure stitch from 3.34 to $1.60(\mathrm{~mm} / \mathrm{kg})$, for the staggered stitch from 3.58 to $0.10(\mathrm{~mm} / \mathrm{kg})$, for the binder stitch, respectively, from 3.74 to $2.0(\mathrm{~mm} / \mathrm{kg}$ ) (Table 2).

It was established that the average compliance of the cotton thread is less than of the polyamide thread. The minimum average stitch compliance is characteristic for a staggered stitch, regardless of the type of thread. The coefficient of compliance for the cotton thread proved to be constant for different types of stitches, while for the polyamide thread the maximum coefficient is inherent for a staggered stitch.
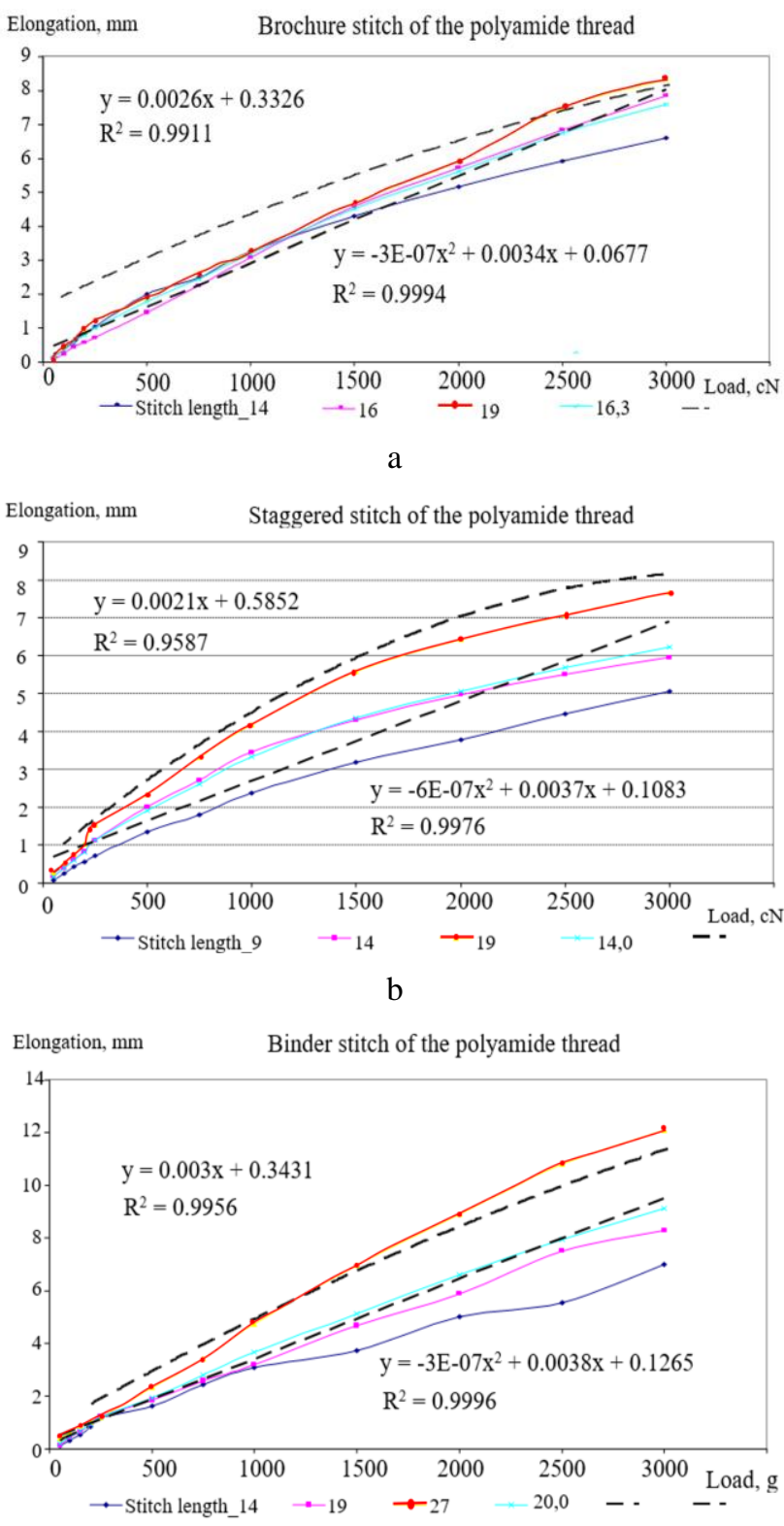

C

Fig. 12 The dependencies of the elongation of the polyamide thread $(\mathrm{mm})$ depending on the load on the brochure (a), staggered (b) and binding (c) stitches

Table 2

Compliance $(\mathrm{mm} / \mathrm{kg})$ for different stitches and threads

\begin{tabular}{|c|c|c|c|c|}
\hline \multirow{3}{*}{$\begin{array}{l}\text { Type of } \\
\text { the stitch }\end{array}$} & \multicolumn{4}{|c|}{ Type of the thread } \\
\hline & \multicolumn{2}{|c|}{ Cotton } & \multicolumn{2}{|c|}{ Polyamide } \\
\hline & $\begin{array}{c}\text { Compliance } \\
\text { range } R \\
(\mathrm{~mm} / \mathrm{kg})\end{array}$ & $\begin{array}{l}\text { Aver- } \\
\text { age }\end{array}$ & $\begin{array}{c}\text { Compliance } \\
\text { range } R \\
(\mathrm{~mm} / \mathrm{kg})\end{array}$ & $\begin{array}{l}\text { Av- } \\
\text { er- } \\
\text { age }\end{array}$ \\
\hline $\begin{array}{l}\text { Brochure } \\
\text { stitch }\end{array}$ & 2.32 & 2.0 & 1.74 & 2.6 \\
\hline $\begin{array}{l}\text { Staggered } \\
\text { stitch }\end{array}$ & 2.32 & 1.7 & 3.48 & 2.1 \\
\hline $\begin{array}{l}\text { Binding } \\
\text { stitch }\end{array}$ & 2.32 & 2.4 & 1.74 & 3.0 \\
\hline
\end{tabular}

So, the effort to pull out the book section from the block using stitches of polyamide thread is larger than that of a cotton thread.(Table 3) Moreover, when sewing book sections with a staggered stitch the pulling force is greater 
than when applying a simple binder stitch, and therefore the editions will be long lasting in use.

It should be noted that the effort to pull out the book section from the block increases with the increase of the stitch length.

Table 3

The pulling force $F, H$, for the transpose bookbinding stitch

\begin{tabular}{|c|l|l|}
\hline \multirow{2}{*}{ Stitch length $d, \mathrm{~mm}$} & \multicolumn{2}{|c|}{ Type of the thread } \\
\cline { 2 - 3 } & Polyamide & Cotton \\
\hline 19 & 285.8 & 173.1 \\
\hline 16 & 197.6 & 153.5 \\
\hline 14 & 93.1 & 73.5 \\
\hline 22 & 372.4 & 196.1 \\
\hline 27 & 420.8 & 206.3 \\
\hline
\end{tabular}

Consequently, the best performance has been shown by a transpose bookbinding stitch made from polyamide thread.

Thus, in the course of research, the character of the damage of the surface of cotton and polyamide threads, with the help of which the process of sewing book sections of book blocks on modern thread sewing machines takes place has been revealed, and the influence of the physical and mechanical properties of threads and their stitches on the strength of book editions fastening has been established.

\section{Conclusions}

In this study was done the brochure block binding with reduced threads surface friction coefficient, physicalmechanical parameters analysis. It was established the cotton and polyamide threads elongate when the tensile forces influence.

Was investigated the mechanical parameters of the bound brochure depending on the type of thread and the stitch distance. It was found that using a polyamide thread with a $27 \mathrm{~mm}$ distance achieves a maximum pulling force of $420.8 \mathrm{~N}$, while in the case of a cotton binder thread and the same stitch distance, the pulling force is much lower, reaching $206.3 \mathrm{~N}$.

The obtained results are useful and can be used to improve brochure and book binding technologies.

\section{Acknowledgements}

The work has been supported by the agreement between Kaunas University of Technology and Ukrainian Academy of Printing in Lviv. On cooperation in reseach and tuition in the area of printing and packaging technologies.

\section{References}

1. Andrushchenko, V. V. 2009. Study of reliability of thread-sewing machine BNSH-6A, Technology and Technique of Typography 3: 52 - 57 (in Ukrainian).
2. Gouldsteyn, Dzh. 1984 Scanning electron microscopy and X-ray microanalysis. Moscow: 303 (in Russian).

3. Dolganina, N. Yu.; Sapozhnikov, S. B. 2013. Study of the influence of type weave for strength of the textile armor panel at the local impact, Bulletin of the South Ural State University Series, Mechanical Engineering Industry 13(2): 95-104.

4. Fedorova, E. E.; Safonov, P. E.; Fetisova, O. N.; Yuhin, S. S. 2011. Research of strength reduction of aramide fibers for manufacturing fabrics of special purpose, Technology of textile industry 6(335):16.

5. Bazhenov, S. L.; Goncharuk, G. P. 2014. The Influence of water on the friction forces of fibers in aramid fabrics, Mechanics of Polymers, Polymer Science, Series A, 56(2): 184-195.

6. Havenko, S. F.; Logazyak, I. Yu. 2009. The study of the strength properties of threads for binding book and magazine blocks, International Conference of Young Scientists, p. 107-108 (in Russian).

7. Havenko, S. F.; Kulik, L. I. 2000. Research of technological properties of threads for fastening of book blocks and estimation of their quality, Ukrainian Academy of Printing. Lviv, Sientific Papers 2: 52-55 (in Ukrainian).

S. Havenko, E. Kibirkštis, L. Gegeckienè, S. Khadzhynova, M. Kadyliak

\section{INFLUENCE OF STRUCTURE AND PHYSICAL- MECHANICAL CHARACTERISTICS OF THREADS ON THE STRENGTH OF BINDING THE BOOKS}

S u m m a r y

In this study was analyzed the physicalmechanical properties and characteristics of different type of threads (polyamide, cotton) for blocks sewing.

Investigated the brochure block binding with reduced threads surface friction coefficient, physicalmechanical parameters analysis. An important step in calculating the strength of threads for book sections and book blocks sewing is the choice of the strength criterion. For this purpose, are analyzed the influence of the structure of cotton and polyamide threads antifriction.

Here was made the book binding process optimization with different types of the thread. It has been determined that the strongest book binding is with the polyamide type thread.

Keywords: binding sewing the books, cotton and polyamide threads, mechanical characteristics, bookbinding stitches.

Received February 13, 2019 Accepted August 26, 2019 